\title{
SOCIOLINGUISTICS AND FIRST LANGUAGE TEACHING
}

\author{
Ray Mc Cormick \\ English Department, University of Cape Town
}

My years of primary and secondary school teaching have led ne to believe that if new ideas or frameworks are to be useful to teachers, their introduction should

(i) not only provide an outline of the nature of the ideas but also Eive examples of the waye in which they could be of practical use to teachers

(11) present both outline and examples in such as way as to equip teachers to generate further applications that would be relevant to the particular challenges and resources of their own situation.

This paper has been planned to meet both of these criteria. After a brief introduction to the field of sociolinguistics two focal areas will be described and their relevance to first language teachers discussed.

\section{What is sociolinguistics?}

Broadly speaking, sociolinguistics is the study of language in its social context. It is a relatively young sub-discipline within linguistics, having been recognised as guch in 1964 at a conference at Georgetown University in Washington D.C. Its guestions and modes of enquiry have roots in Anthropology and soolology. AB this might suggest, sociolinguistics is concerned with language use (by individuals and as societal markers of events, groupings and relationships) in both small, non-industrialised communities and large industrialised societies. 
The scope of enquiry varies from what Fishman called macro to micro sociolinguistics ${ }^{1}$. The former would cover, for example, issues in language policy-making in various countries, while an example of the latter would be the detailed analysis of a twenty minute conversation to show linguistic aspects of topic control.

Underlying questions in sociolinguistics are:

how do existing social and economic relations affect the use of language?

And the converse:

how does language reflect these relationships and any resistance to them?

These underlying questions generate a related set of more specific ones:

who speaks?

to whom?

about what?

why?

in what circumstances?

how?

with what effect?

And then there is the implied converse set in which the first guestion becomes "Who is silent?", while the rest remain.

Critical linguistics, a fairly recent off-shoot of sociolinguistics, has as its main interest the uncovering of power relationships as manifested in language. Looking at linguistic text (written or spoken), critical linguists would ask, in addition to the underlying questions listed above:

in whose interest is it that the discourse and its particular features should be as they are?

(For an account of the use of critical linguistics in language teaching see Janks 1991.)

Sociolinguistic research methods include: case-studies using participant observers (for example, Denison's study of the use 
of language in various domains of everyday life in a small trilingual community in Italy ${ }^{2}$ ); large-scale surveys with narrow fool (for example, Labov's study of the use of prestigious and stigmatised variants of a particular coneonant as an indicator of social etratification in New York ${ }^{3}$ ); interviews that attempt to uncover the dynamics of inguletic attitudes and practices (for example the Mercer, Mercer and Mears study of young Asian people in Leicester ${ }^{4}$ ); detalled linguistic and interactional analysis of recorded speech (for example, Swann's study of the problems of analysing male dominance in claesroom conversation ${ }^{5}$ ).

What kinds of insight can conversation analysis provide?

Let us return to the sets of questions given above and look at how they can be applied in the analysis of conversation to draw attention to linguistic features, discourse strategies and underlying societal relationships. Below we have the opening lines of a short dialogue. ${ }^{6}$ If we ask "Who speaks to whom about what, how, with what effect, and why?" where does it lead us?

What "s your nane, boy?

Dr Pouissant. I'm a physician.

What's your first name, boy?

Alvin.

Using our internalised knowledge of the norms of conversation between strangers, let us examine the details of this conversation to see what provides the cues to our interpretation of it as primarily a power contest although superficially it looks like a successful request for information. (I have found that this hind of analysis is one that students can pick up rapidly and use effectively on both real and literary dialogue: it gives them specific points of reference. More detail concerning these points is provided in 
the last section of the paper.) Initially this analyeis entalls articulating the obvious in order to make people aware of the sociolinguistic framework they operate with every day. I will now take you through the obvious.

There are several unusual features in the conversation. The firet line breaks the rules for opening gambits in street encounters in an English-epeaking society because it is personal. Opening gambits are normally impersonal unless between an adult and a child. The unnamed speaker asks two questions, the second an uncommon one to be asked so soon of a person met on the street. This speaker uses a term of address that is clearly not age-related as the person to whom it refers is old enough to have had several years of tertiary education. Dr Foulseant responds to the first question, giving essential information and adding additional, unsolicited information to which the firet speaker makes no response. The doctor does not use a term of address to his interlocuter, nor does he, when asked for his name, reciprocate by asking the other speaker's name - which is what commonly happens if one person aske.

The first speaker controls the initiation and direction of the conversation: he asks the questions and he positions the listener by calling him "boy". The unsolicited information provided by the second speaker about his prestigious profession is clearly a move towards resisting the positioning as an inferior. There is an obvious lack of reciprocity in addreas and in type of conversational turn. Why does the Doctor respond at all, even to the first question? And why to the second one? Why is an educated man so compliant in the face of rude, invasive questions? To anewer these particular manifestations of the basic set of sociolinguistic questions we have to move beyond the linguistic data to the society. If you know that this dialogue took place on a street in an American city in the $1960^{\circ} \mathrm{s}$, all the questions are answered at once by referring to the social structure which placed a policeman in a 
position more powerful than that of a phyelcian if the policeman was white and the doctor black.

What kinds of insights are Erovided by language attitude Etudites?

It is well known that the socio-economic status of the majority of speakers of a particular language often affects the willingness of speakers of other languages to lieten to and respect what is said by an individual speaker of that language. What is at issue is not just a question of intelligibility: if this speaker is talking in what is his or her second or third language, and has an accent which indicates the home language, it can affect listeners response positively or negatively.

Take, for example, a person using French-accented. Englieh in the company of native-speakers of English in South Africa. The response would probably be positive, interested, forgiving of errora. Why? Fartiy because the French people who come to South Africa are of relatively high socio-economic status, on the whole. And partly because of the legendary romantic, gastronomic and other cultural achievements that "The French" are renowned for. Would the same openness be likely to be extended to a speaker whose accent in English indicated a mother toneue which was the language of a people whose socioeconomic status was generally low, and whose culture was not valued? And would this second person have felt as willing to speak on a public occasion or to strangers as the French person would? The knowledge that they are likely to be negatively stereotyped and therefore not properly listened to often silences people.

Everything that I have said above applies also to different dialects of a language. Studies have been done of the images triggered in the minds of listeners by the different accents of tape-recorded voices speaking or reading about topics that are 
not revealing of the speaker's background ${ }^{7}$. Interesting findings are that attitudes are often ambivalent. One listener may rate $R P^{8}$ accented speech highly on assumptions about the speaker's wealth, level of education, ambition, intelligence on the one hand, and, on the other, rate this speaker low on qualities such as friendliness, sincerity, honesty, sense of humour, masculinity. By the same token, an overtly low-status accent may trigger low ratings on the first set of features mentioned above and high ratings on the second set of qualities. Thus it can be seen that a dialect or an accent may enjoy both overt and covert prestige. This goes some way to explaining why some individuals retain their low-status dialects or accents even when they do control the standard dialect and had sufficient opportunity pre-puberty to have developed a higher status accent. Their original accent or dialect is a marker of their group identity. (Cheshire writes very interestingly on adolescents use of non-standard speech as indices of group solidarity ${ }^{9}$ )

What are the applications of the questions and findings mentioned above in the school situation?

Three spheres of the teacher's work will be discussed:

(a) the relationship between school policies and staff, pupils and community

(b) language teaching

(c) literature teaching

(a) School and community relationships

If the language that you teach as first language is not the language of the school administration and is associated with low status, you may find that the parents of your pupils, fearing poor reception of their speech, do not come to consultation evenings, do not volunteer for school committees 
and do not talk at PTSA or PTA meetings. They may also avold writing notes to you explaining their child's abanee from school. Another possibility is that, while they might be willing to try, their children, being ashamed of their parents. command of the school's language of adminietration, do not pase on information about meetings and school events and do not hand in the "absence notes" imperfectly written by their parents.

If the Echool's structures, staff and other pupils place little importance on the language you teach, your L1 pupils and their parente may become alienated. If pupila feel marginalised it is likely to affect motivation to study and to do well. There are Beveral ways in which the school's low evaluation of the language's importance shows: poor budgetary resources, unpopular timetable slots, less rigorous search and selection processes for teachers are some examples.

If the language you teach is the language of the school administration and a medium of instruction, then the problems of stereotyping on the basis of dialect difference may come into play. Children who speak a low-prestige dialect may be mocked by their peers, or made to feel by means of insensitive prescriptive language teaching, that they and their parents are somehow inferior because they "can't speak (or write) properly". The range of effects on their parente" participation in school events would be similar to that described above as pertaining to speakers of low-status languages.

It is a depressingly common belief among people who have had no contact with Linguistics that non-standard dialects are the manifestation of collective and individual inability to think logically. Such people often believe that non-standard dialects are not rule-governed, are very limited in what they allow to be said (or thought), or are a random collection of eccentricities or errors inimical to abstract thought and to 
aesthetic creation. Because I think that sociolinguistic reaearch findines can effectively challenge these potentially damaging beliefs, I would like to see a sociolinguistic component in the training of all teachers, not just in the teachers of languages. I have argued this elsewhere ${ }^{10}$. Useful books dealing with these issues are Peter Trudgili' $\boldsymbol{\theta}$ Accent. Dialect and the School and John Edwards's Language and Disadvantage.

\section{(b) Language and literature teaching}

Besides the insights into school and community relationships that sociolinguistics can provide, it can also be of aseistance to first language teachers in the classroom. There are two main areas in which it is particularly useful. One is in giving the kinds of insights that help them to deal creatively with the tensions between the need to equip pupils with competence in the standard dialect and in formal discourse and the need to take cognizance of other dialects and registers. The other is in equipping teachers to use as teaching material the wealth of interesting material inherent in ordinary discourse. This in turn should help to create among pupils a greater openness and sensitivity to different uses and users of their language.

The study of sociolinguistics and other branches of linguistics should enable the teacher to discover and describe the social rules and characteristic patterns in the use of different acoents, lexical pools, conversation strategies. The teacher is then in a position not only to see the standard dialect and formal register as appropriate in some circumstances and not in others - something that many teachers feel intuitively - but also to describe the soctal norms and linguistic features characteristic of other forms of the language ueed appropriately. Pupils can then encounter clear descriptions of the patterns, see them as interesting social indicators, and 
draw on recognised sets of questions for approaching the analyeis of language use in a particular situation. In my experience people find it exhilarating to reflect on the familiar and the ordinary, to look at the language they have always looked through.

Let me now be concrete and give examples. Transcripts of nonstandard dialogue (taken from life or literature) can be searched for grammatical regularities which are the gign that rules different from those of the standard dialect are in operation. Depending on the age of the puplls, the teacher could either be satisfied with the recognition of the patterns and differences, or prompt the pupils to find worde to describe the patterns. This kind of exercise can facilitate the learning of grammatical terms because the studente see that they need them.

Teachers of English as first language might usefully analyse examples of Rap to reveal features of poetic language (in Jakobsen's sense - i.e. where the emphasis is on the form). The delights and demands of highly polished verbal skills can thus be seen to be within the abilities of speakers of lowprestige dialeots, contrary to popular belief. Using material from Rap culture could also provide the opportunity for talking about the kinds of verbal behaviour that are valued in different societies - in a society that produces good Rap tough young males power resides largely in their ability to play creatively and rapidly with words in tense situations, knowing the rules of the different genres ${ }^{11}$. There are other societies where the powerful young male is not "the man of words", but "the strong silent guy".

Sociolinguistic knowledge about attitudes to different languages and dialects can be drawn into analysis of dialogue in literary texts. The use of different dialects in literary dialogue can be examined for its role in "placing" characters 
as belonging to a particular region or class. It may indicate to the reader what the writer's atifude was to epeakers of certain dialects. In the text do speakers of low-status dialeots ever epeal articulately on serious topics? Are they seen to be wite or only the butts of humour?

Analysis of conversational etrategies can develop in students a ereater sensitivity to the linguietic detalls that are indices of relationehips of equality and inequality. We saw some of these details in the extract of dialogue examined earlier. Longer extracts would provide a greater range of cues. A check-list of the aspects of dialogue that are revealing of social relations can be very useful but it is not mechanically applicable: it has to be used within a framework of knowledge of what the norms of appropriate conversation are for the society from which the speakers come. Let us run through the factors in typical conversations to see how each can have something to show about the relationships between speakers. This kind of analysis can illuminate both real life and literary dialogue. (Again the need to articulate what it was in the language that prompted the student's intuitive interpretation of the converation's dynamics may lead to the effective absorption of grammatical terminology.)

The greeting Who.greets whom first? Does this follow or challenge the normal pattern in that society, for example the older person greeting the young one first, or vice versa?

The terms of address Are these used symmetrically or asymmetrically: do both use first names, or does one use a nickname and the other uses only a title (such as "doctor", "uncle")?

Pronouns Who is included in a speaker"s use of "we" and who is distinguished as "they": how is the "us/them" division constituted? In a language which has two forms 
for the second person pronoun, which is ueed and is it used reciprocally?

Language choice If the epeakers speat more than one language whlch Bpeaker chooses the language for this conversation? Is the choice resisted by other efeakers? Is the cholce unusual for the situation or domain?

First topic choice who sets the firet topic? Would it have been possible for another speaker to have set it? If not, what are the constraints - the nature of the situation (e.g. the school principal summoning and reprimanding a puptl for bad behaviour), or the nature of the relationship (e.g. the managing director and a new junior employee)?

Topic change Are all participants equally free to change the topic of conversation? If not, what are the constraints?

How does topic changing occur? By formal signalling (e.g. "We will now move on to the next item on the agenda.")? After a pause?

How does speaking turn change? By interruption? By invitation? After a pause? Are all the strategies used equally by all speakers? If not, what do the differences suggest about the speakers attitudes to one another?

Jength of speaking turns Are these roughly equal? If not, what might account for the differences?

Types of utterance (for example questions, statements, commande, demands). Are these roughly equally distributed among speakers? If not, what do the striking inequalities sugEest sbout the speakers relationships to one another or about their positions in the society at large?

Confldence levels. Who seems to be the most and who the least confident speaker? What is it in their speech that gives this impression - relative loudness or fluency, modality markers, preferred turn types or turn-changing strategies?

Termination How is the conversation terminated? If by 
one person, and it is not resisted, what accounts for that?

The necessary social knowledge about epeaking rightg in particular stugtions in one's own speech community is often below the level of consciousness. Transgressions of the norme make them vialble. Equivalent social knowledge about other speech communities is more difficult to obtain and to impart but without it, without knowing, for instance shich grounds for social stratification (caste, gender, age, clase, race, education, religion, wealth) are the most powerful in the speech community, a conversation analyet might well be floored by apparent anomalies - the policeman referring to the adult physician as "boy", for example.

The diecipline of sociolinguistics has something to offer LI teachers some of whose pupils may, in fact, pot be Li epeakers, but that would be another paper. We have looked at only two areas of sociolinguistics which could be of use to first language teachers. There are many more. Lach of time prevents me from advancing more evidence in support of my contention that sociolinguistics provides accessible and productive routes into the fascinating terrain of the relationship between social factors and linguistic forms. I hope you and your students will try some of these routes. 


\section{FOOTNOTES}

1. Fishman (1972). In the interests of economy for those who might wish to read further, I have taken the following two examples from the game readily available anthology.

2. Denizon (1972).

3. Labov (1972).

4. Mercer, Mercer and Mears (1979).

5. Swann (1988).

6. Ervin-Tripp (1972) P 225.

7. Giles and Powesland (1975).

8. RP is an abbreviation for "Received Pronunciation" which ie a highly prestiglous accent of British English, the one that used to be associated with BBC news-readers.

10. Mccormick (1978);

11. Abrahams (1974). 


\section{BIBLIOGRAPHY}

Abrahams, R. (1974) Black talking on the streets. In R.Bauman and $J$ sherzer (eds) Eurplonations in the ethnography of zeeatine, Cambridze: Cambridge University Fress.

Cheshire, J. (1978) Present tense verbs in Reading English. In P. Trudgill, (ed.) Sociclinguistic natterns in British English. London: Edward Arnold, pp 52-68.

Denison, N. (1972) Some observations on language variety and plurilingualism. In J.B. Pride and J. Holmes Soctolineuistics. Harmondsworth: Penguin, pp 65-77.

Edwards. J. R. (1979) Language and digadvantage. London: Edward Arnold.

Ervin-Tripf, S. (1972) Sociolinguistic rules of address. In J.B.Pride and J. Holmes op cit, PP 225-240.

Fishman, J.A. (1972) The relationship between micro- and macrosociolinguistics in the study of who speaks what language to whom and when. In J.B.Pride and J. Holmes op cit, pp 15-32.

Giles, H. and Powesland, P.F. (1975) Speech style and social evaluation. London: Academic Press.

Janks, H. (1991) A critical approach to the teaching of language. In Educational Review Vol. 43 no. 2.

Labov, $W .(1972)$ The study of language in its social context. In J.B.Pride and J. Holmes op cit, PP 180-202.

MoCormick, K. (1383) The value of a sociolinguistic component in teacher education, with particular reference to Cape Town, South Africa. Unpublished paper given at the third annual International Seminar for Teacher Education in the $80^{\circ} \mathrm{s}$ and $90^{\prime} \mathrm{s}$, held in Harper's Ferry USA.

Mercer, N., Mercer, E. and Mears, F. (1979) Linguistc and cultural affiliation among young Asian people in Leicester. In H. Giles and B. Saint-Jacques (eds) Language and ethoic relations. Oxford: Pergamon Press, pp 15-26.

Swann, J. (1988) Talk control: an illustration from the classroom of problems in analysing male dominance of conversation. In J. Coates and D. Cameron (eds) Women in their speech communities. London and New York: Longman, pp 122-140.

Trudgill, P. (1975) Accent, dialect and the school. London: Edward Arnold. 